\title{
Two views on invasive ants
}

\author{
M. Breed ${ }^{1}$
}

Published online: 5 July 2016

(C) International Union for the Study of Social Insects (IUSSI) 2016

Human actions that break down natural barriers or transport species across those barriers have the serious consequence of creating the start of biological invasions. Social insects play a large role in the overall picture of biological invasions, with many species of ant, including fire ants, Solenopsis invicta, and Argentine ants, Linipithema humile, wreaking havoc on ecosystems. Wasps, such as Polistes dominula and Vespa velutina, have gained serious footholds in non-native habitats. The Formosan termite, Coptotermes formosanus, is equally a scourge. Even the honey bee, Apis mellifera, whose introduction into the New World is often seen as a benign event and whose current presence is valued for its role as a pollinator, has had dramatic effects on native bees and possibly on plants that rely on native bees for pollination.

In this issue two papers highlight different aspects of social insect invasion biology. Calcaterra and colleagues (2016) take on the original community roles of ants that become invaders by comparing ecological dominance among ants in both native and introduced communities. They take advantage of the natural occurrence in Argentinian ecosystems of several prominent invasive ant species, including two of particular note, Solenopsis richteri and $L$. humile. These two species are ecologically co-dominant in the Otamendi Natural Reserve, near Buenos Aires, Argentina, with $S$. richteri being numerically the most abundant ant and $L$. humile being the best at recruiting to new food sources. However, these ants co-exist in this reserve with 47

M. Breed

michael.breed@colorado.edu

1 Department of Ecology and Evolutionary Biology, The University of Colorado, Boulder 80309, Colorado, USA other species of ant, including several that are also invasive, suggesting that ecological resistance to the qualities that favor invasive success have evolved among ants in these communities. Competition may not be the primary factor in structuring these communities, reducing the impact of species with high competitive abilities. These two invasive species were abundant across several habitat types, suggesting that they are ecologically flexible. Three noninvasive species were also dominant in the habitats, meaning that the characteristics that lead to invasiveness are not the sole qualities that lead to dominance in a native habitat, although the invasive potential of these other species is unknown.

Santos (2016) reviews the roles of ants in urban ecosystems. In a descriptive analysis based on over 100 papers published about ants found in urban environments, Santos found that many known invasive ants, including $S$. invicta and $L$. humile are also prominent in the literature on urban ants. Other invasive ants occurring in urban environments include the pharaoh's ant, Monomorium pharonis, and Tapinoma sessile. The majority of the studies of urban ants came from the United States (with a bias towards southern and northeastern states) and Brazil (with a bias to southeastern Brazil). While urban ants are more often aesthetic pests rather than vectors of disease or destroyers of food supplies, some species present public health problems by stinging or being incidental purveyors of bacteria and fungi. Their presence in urban environments is thus a concern due to public demand for control and in some cases public health concerns.

For those of us whose interest lies in the beauty of social insects' complex systems of communication and division of labor, as well as their major significance in terrestrial ecosystems, rather than in applied entomology, reading 
these two papers is a dark reminder that introduced social insects can have significant negative impacts on both humans and natural communities. By the translocation of ants across geographic barriers of oceans and mountain ranges that would be otherwise impassable for ants, humans have created real problems of immediate importance. Transfers of social wasps, social bees, and termites have happened in much the same ways as for ants. These movements have largely resulted from inadvertent actions or carelessness with shipment sanitation and quarantine. We cannot unreel these past actions; in fact, more than half a century of futility in trying to control fire ants and the "Africanized" version of the honeybee suggest just the opposite. Biologists who work on social insects should have much to bring to discussions of how to ameliorate the impacts of social insect populations as they become established in natural communities and in urban environments.

\section{References}

Calcaterra L, Cabrera S, Briano J (2016) Local co-occurrence of several highly invasive ants in their native range: are they all ecologically dominant species? Insect Soc. doi:10.1007/s00040016-0481-3

Santos MN (2016) Research on urban ants: approaches and gaps. Insect Soc. doi:10.1007/s00040-016-0483-1 